\title{
Closing the treatment gap for depression co-morbid with HIV in South Africa: Voices of afflicted women
}

\author{
Inge Petersen ${ }^{1 \#}$, Jill Hanass Hancock ${ }^{1}$, Arvin Bhana ${ }^{1,2}$, Kaymarlin Govender ${ }^{1}$, \\ Members of Programme for Improving Mental Health Care (PRIME) ${ }^{3^{*}}$ \\ ${ }^{1}$ University of KwaZulu-Natal, Durban, South Africa; ${ }^{\#}$ Corresponding Author: peterseni@ukzn.ac.za \\ ${ }^{2}$ Human and Social Development, Human Sciences Research Council, Durban, South Africa \\ ${ }^{3}$ Research Programme Consortium, Department for International Development (DFID), London, UK
}

Received 15 January 2013; revised 28 February 2013; accepted 6 March 2013

\section{ABSTRACT}

This Background: In South Africa the rising comorbidity of mental disorders with other noncommunicable and communicable diseases, particularly in people living with HIVIAIDS (PLWHA), has helped raise the public health priority of mental ill-health. Depression, in particular, compromises anti-retroviral treatment (ART) adherence and virological suppression, thus threatening the effectiveness of South Africa's ART programme. Given that evidence-based treatment for depression comprises medication and/ or Western-derived psychotherapies, responding to the current interest in expanding mental health services for PLWHA demands an understanding of how best to provide culturally competent care within existing resource constraints. Aim: To explore the context and local understandings of depression in women living with HIV to inform the development of contextually appropriate mental health services that could be delivered within existing resource constraints in

"PRIME members include Crick Lund (University of Cape Town, South Africa), Mark Tomlinson (Stellenbosch University and University of Cape Town, South Africa), Vikram Patel (London School of Hygiene and Tropical Medicine, United Kingdom), Abebaw Fekadu (Addis Ababa University, Ethiopia), Rahul Shidhaye (Public Health Foundation of India), Mark Jordans (HealthNet TPO), Inge Petersen (University of KwaZulu-Natal, South Africa), Arvin Bhana (Human Sciences Research Council, South Africa), Lara Fairall (University of Cape Town, South Africa) Fred Kigozi (Makerere University, Uganda) Martin Prince, Graham Thornicroft and Charlotte Hanlon (Institute of Psychiatry, King's College, London, United Kingdom), Mary De Silva (London School of Hygiene and Tropical Medicine, United Kingdom), Ritz Kakuma (University of Melbourne, Australia; University of Cape Town, South Africa), David McDaid (London School of Economics, United Kingdom), Shekhar Saxena and Dan Chisholm (WHO), Shoba Raja and Sarah Kippen-Wood (Basic Needs, India and USA), and Simone Honikman (University of Cape Town, South Africa).
South Africa. Method: Semi-structured qualitative interviews were held with $\mathbf{3 5}$ women living with HIV in South Africa who met the diagnostic criteria for a major depressive disorder. Results: Being HIV-positive per se was not reported to be a major cause of depression. Instead, a number of social factors were reported. These included stigma and discrimination, poverty, and stressful life events. Symptoms of depression, especially social withdrawal, negative ruminating thoughts and excessive worry suggestive of comorbid anxiety, functioned to exacerbate and trap women in a negative depressive cycle. Social support emerged as a dominant coping strategy. Group-based interventions, which afford greater opportunities for improved social support, were mooted as the most appropriate intervention by the majority of participants. Individual counselling provided through a home visitation programme was suggested for those who were too ill or too poor to attend clinics. Task sharing was also endorsed. Conclusion: The need for multisector engagement in mental health promotion to address factors that trigger, maintain and exacerbate depression at a community level in PLWHA is highlighted. The triggers, symptoms and local coping strategies employed by afflicted women in this study suggest a resonance with Western derived evidence-based psychological therapies. In relation to delivery channels, there was support for the provision of group interventions or home-based individual counselling using a task sharing model.

Keywords: Depression; Mental Health; HIV AIDS; South Africa 


\section{INTRODUCTION}

The call by the global mental health movement to increase access to mental health services has been spurred by the rising burden of mental, neurological, and substance use (MNS) disorders, which account for 13\% of the global burden of disease [1] and the large treatment gap for these disorders. This gap is particularly high (up to $90 \%$ ) in low and middle income countries (LMIC) [2].

South Africa, an upper middle-income country has a treatment gap of $75 \%$ for common mental disorders [3]. It also has one of the highest HIV burdens in the world. Concern over the rising co-morbidity of mental disorders with other non-communicable and communicable diseases, particularly in people living with HIV/AIDS (PLWHA) has served to raise the public health priority of mental disorders in this country [4,5]. Common mental disorders (CMDs) co-morbid with HIV/AIDS are of concern to the South African Department of Health as they threaten to undermine the success of the country's antiretroviral therapy (ART) programme, the largest in the world [5]. This is because: 1) CMDs increase risk for poor ante-retroviral treatment (ART) adherence. A review of 23 studies in sub-Saharan Africa reveals that good adherence is 55\% less likely in HIV-positive patients with depressive symptoms than those without [6]. In SA specifically, a recent study confirms this association [7]; 2) Depression and stressful life events are independently associated with accelerated disease course, with psychosocial factors linked to immune suppression [8].

Common mental disorders (CMDs) are the most frequently observed disorders in PLWHA, with depression having the highest prevalence, followed by anxiety, posttraumatic stress disorder (PTSD) and alcohol abuse [9, 10]. Major depressive disorder prevalence rates range from $11.1 \%$ [11] to 34.9\% [12] in PLWHA in South Africa.

While the recent South African National Strategic Plan on HIV, STIs and TB (2012-2016) [13] identifies the need for counselling and mental health services for PLWHA, how to scale up effective services for CMDs in the context of South Africa's constrained specialist mental health resources [14], remains unclear. A systematic review of international evidence indicates that effective interventions for depression in PLWHA include psychosocial interventions with a cognitive behaviour component or psychotropic drugs; with a combination of the two types of interventions being the most effective [15]. Current legislation in South Africa demands that psychotropic medication be initiated by medical practitioners. This limits accessibility given the scarcity of medical practitioners in primary health care. Further, there is growing criticism of the medicalization of the treatment of depression [16] given clear evidence of the social determinants of depression [17]. The need for an expansion of counselling services for co-morbid depression as ar- ticulated in the South African National Strategic Plan on HIV, STIs and TB (2012-2016) is thus endorsed. This is especially so in light of evidence that it can be effecttively provided using a task sharing approach whereby specialist functions are shared with non-specialists [18]. There is evidence of the effectiveness of cognitive-behavioural therapy (CBT), interpersonal therapy (IPT) and problem-solving therapy (PST) for treating depression within non-specialist settings [18].

The need to understand the most appropriate therapeutic modality/combination of these modalities for PLWHA in South Africa is, however, important to inform their translation to ensure culturally competent care for the South African context. Culturally competent care refers to care where service providers strive to provide care within service users' cultural framework and social realities [19] and is important to ensure service user acceptability, uptake and adherence. This requires an understanding of local idioms of distress and healing with respect to depression in PLWHA in South Africa.

In the context of an overburdened primary health care (PHC) system as well as limited specialist mental health personnel, there is also a need to understand mental health promotion interventions that can assist to prevent the development of depression in PLWHA at a community level as well as the acceptability of task sharing. Task sharing is promoted by the World Health Organization (WHO) and the global mental health movement as a mechanism for increasing access to mental health services in LMIC [20]. Task sharing is endorsed by the South African National Health Care Plan [21]. However, in relation to mental health services, the composition of treatment packages for CMDs, and roles and responsebilities of different health care providers in the delivery of different components of these packages requires clarification [22].

The aim of this exploratory study was thus twofold: 1) To understand the context and local understandings of depression in women living with HIV with the view to informing the content of a care package for depression that would be culturally acceptable; and 2) To develop an understanding of how best to deliver this package using a collaborative care task sharing approach within existing resource constraints. The scope of this study was limited to depression in HIV-positive women given that: 1) depression poses the greatest burden of mental illness in PLWHAs; 2) there is a higher prevalence of HIV/AIDS in South African women; and 3) there is a higher prevalence of depression in women in the general population [23].

\section{METHODOLOGY}

\subsection{Study Sites}

The study sites were two HIV/AIDS Clinics, one in 
KwaZulu-Natal and one in the North West Province of South Africa. Both health facilities served peri-urban populations, with the ante-natal prevalence for KwaZuluNatal and North West Province in 2010 being 39.5\% and 29.6\% respectively [24]. Both facilities provided HIV Counselling and Testing (HCT) as well as ART services for PLWHA.

\subsection{Study Design}

A qualitative focused ethnographic approach was adopted using Kleinman's concept of explanatory models of illness [25] as a broad framework for guiding the interview questions. Ethnographic research is associated with field studies using observation and in-depth interviews which aim to describe and interpret a culture, system or social group. Focused ethnography is used for the rapid and intensive collection of information on a specific focused issue [26].

\subsection{Recruitment and Sample Description}

The study was explained to service users attending the HIV clinics by field workers who were then formally invited to participate in the study. Following informed consent procedures, potential participants were recruited from the waiting room over a period of one month over four randomly chosen days in each site. A first stage screening instrument for common mental disorders, the Self Reporting Questionnaire-20 (SRQ-20), previously validated in South Africa was administered to potential participants [27,28], using a cut- off point of 8 or above. The second stage diagnostic screen used the depression module of the Structured Clinical Interview for DSMIV Diagnosis (SCID) for major depressive disorder (MDD). This instrument has also previously been used in South Africa [29] and was administered by mental health specialists who had received training and supervision in the use of this assessment tool.

Additional inclusion criteria were that women were not pregnant at the time of the study or had not delivered a baby in the last 6 months, had tested HIV+ previously, were 18 years or older, did not need urgent medical attention, and were competent to participate in the interview, i.e., did not have difficulty with hearing, speaking, or cognition. Participants with severe depressive symptoms and/or suicidal ideation were immediately referred for treatment. Twenty participants from the site in KwaZulu-Natal and fifteen from the site in the North West Province, were finally recruited into the study. The demographic characteristics of the final sample are described in Table 1.

\subsection{Data Collection}

In-depth individual interviews were conducted to elicit
Table 1. Demographic characteristics of participants.

\begin{tabular}{|c|c|c|}
\hline Demographic & $\mathbf{N}=35$ & Percentage \\
\hline Age: 18 - 20 & 2 & 6 \\
\hline $21-30$ & 6 & 17 \\
\hline $31-40$ & 11 & 31 \\
\hline $41-59$ & 16 & 46 \\
\hline \multicolumn{3}{|l|}{ Education: } \\
\hline No Schooling & 2 & 6 \\
\hline Primary Education & 5 & 14 \\
\hline Secondary and Post-Secondary & 28 & 80 \\
\hline \multicolumn{3}{|l|}{ Marital Status } \\
\hline Not married & 14 & 41 \\
\hline Married & 6 & 18 \\
\hline Married, living on own & 4 & 23 \\
\hline Cohabiting & 8 & 12 \\
\hline Divorced/ & 2 & 6 \\
\hline \multicolumn{3}{|l|}{ Separated/Widowed } \\
\hline \multicolumn{3}{|l|}{ Employment Status } \\
\hline Employed & 10 & 28 \\
\hline Unemployed (15 receive a social grant) & 24 & 69 \\
\hline Student & 1 & 3 \\
\hline \multicolumn{3}{|l|}{ Housing } \\
\hline House & 30 & 88 \\
\hline Flat & 1 & 3 \\
\hline Rented Room & 3 & 9 \\
\hline \multicolumn{3}{|l|}{ Number Living in Household } \\
\hline Under 16 years: None & 5 & 15 \\
\hline 1 - 3 people & 21 & 64 \\
\hline 4 - 6 people & 7 & 21 \\
\hline Over 16 years: 1 person & 6 & 18 \\
\hline 2 - 3 people & 17 & 50 \\
\hline 4 - 7 people & 11 & 32 \\
\hline
\end{tabular}

participants' explanatory models of illness for depression which included their understanding of the course, symptoms, coping strategies and possible psychosocial interventions. The individual interviews were audio recorded in isiZulu and seTswana (local languages in each province) with the permission of respondents and translated and transcribed into English. Back-translation checks were applied by an independent bilingual English-isiZulu and English-seTswana speaker.

\subsection{Data Analysis}

Guided thematic content analysis using NVIVO was 
used. Data was coded using "a priori” and emergent codes. Kleinman's conceptual framework for explanatory models of illness was used as the overarching "a priori" coding framework for the analysis of the data. Constant comparisons were made across the cases in a progressive process of classifying, comparing, grouping and refining groupings of text segments to create and then clarify the definition of categories, or themes, within the data [30]. The data was coded by two independent coders to verify and ensure reliability of the emergent themes.

\subsection{Ethical Considerations}

Ethical approval was obtained from the Ethics committees of the University of KwaZulu-Natal, and respective Department of Health authorities in the provinces of KwaZulu-Natal and North West

\section{RESULTS}

\subsection{Perceived Causes of Depressive Symptoms and Exacerbating Factors}

\section{Being HIV-positive}

Receiving an HIV-positive diagnosis and being HIVill did not emerge as the main trigger of depression. Only 4 out of 35 respondents suggested that receiving the diagnosis itself was responsible for causing their depressive symptoms. Further, only 3 respondents attributed their depressive state to being physically ill as a result of the virus.

\section{Stigma and discrimination}

A large number of respondents (23) (14 from KZN and 9 from NW), reported experiencing external stigma and discrimination which contributed to their depressive state. This took the form of people making fun of them, insulting them, gossiping about them, not wanting to help them or have anything to do with them:

Others make fun of you when they know your status (crying)...They talk about you behind your back if you have disclosed...And if you have told your children, when they hear this you (feel) ... disgraced... it's because of these talks (stigma and discrimination) (Case 6, KZN).

Some respondents (5 from KZN and 4 from NWP) also reported internalized stigma as contributing to their depression:

It affected me big time-my self-esteem has dropped big time and I just feel like...I'm not worth (anything), like I don't deserve to have a boyfriend you know something like that and it's not even easy to tell my mom about it (Case 4, KZN).

Lack of social support

Lack of social support, particularly not being able to share their problems with family, and partners who refused to let them talk about their problems, ignored them or reprimanded them when they tried to talk to them about their problems, emerged as a key factor which contributed to depressive symptoms in almost half the respondents from both provinces (17) (9 in KZN and 8 from NWP):

...what can I say (what causes my depression) I think it's because at home we are not getting along... He doesn't want to hear about it (my HIV+ status)... I told him to go for testing he doesn't want to and even if I told him that I'm on ARVs he said that he doesn't care and said that he does not want to see these pills in the house... so I'm in this on my own (Case 18, KZN).

Sometimes when you tell someone that you have a problem and it is like this, they will tell you that "you brought it upon yourself and we warned you”. This is very discouraging instead of them offering a supportive ear (Case 22, NWP).

Partner rejection/abuse/abandonment

Partner rejection/abuse and/or abandonment, through either being unfaithful or leaving them to fend for themselves and their children as well as abuse emerged as a trigger of depression in just under half (16) of the participants (8 in NWP and 8 in KZN).

It (depression) is when his girlfriend is telling me that if I'm not sleeping with him, he will end up with her and he will forget about me. That hurt me very badly because I always told him that if you are cheating please do it somewhere else not around me because if you do it around me it very hurtful...Maybe he does it because I'm sick and because she is fresh... (Participant, 18, KZN)

Other family problems

Other family problems were reported to trigger depression in half of participants (17) (9 in KZN and 8 in NWP). These included difficulties in parenting, with children not being respectful; having to care for unwanted orphaned children; conflicts over issues such as finances and substance abuse; and other interpersonal disputes as reflected in the following quotations:

His family (father of my child) neglected my child so much because my partner left the money for my child. It was not that much but his family did some fraud with the money (and) I had to fight with them (Participant 13, $\mathrm{KZN})$.

I have a problem because if the child comes home high after taking drugs. I shout at him and sometimes the neighbours will hear our quarrel. Then I'll be scared to go outside because they now know that I have a child who doesn't listen...He tells me that I'm going to die because I'm HIV positive and I just wish I was dead or think of killing myself and... let him continue with his life because he's a trouble child (crying) (Participant 8, $\mathrm{KZN}$ ) 


\section{Poverty related stress}

Socio-economic deprivation and not having enough money to cover basic needs was reported by over half the respondents (20) (10 in KZN and 10 in NWP) as causing their depressive symptoms. A major concern for most of the respondents was not having enough money to adequately care for their children. As one respondent indicated:

Eeh, it happens that I don't have anything for my children to eat and they will sleep on an empty stomach. It would be better if I was not alive anymore than to see my children suffer like this. If I was not sick I would go and look for job but now I can't (Case 5, KZN).

Trauma and Loss

Trauma and loss emerged as a trigger for depression in a number of respondents (10) (4 in KZN, 6 in NWP). Multiple loss and bereavement was common, with trauma associated with abuse, rape and interpersonal violence being the source of depressive symptoms for a few (4).

I lost my younger brother, G sometime back before my sister $P$ passed away. My sister and another brother passed away 2.5 months after G. My brother passed away on Friday during Christmas followed by $P$ the day after New Year's. I have accepted my brother and G's passing but I cannot forget $P$ (Participant 7, NWP).

\subsection{Symptoms}

A large proportion of the participants reported withdrawing from activities and not wanting to be with others (26) (14 in KZN, 12 in NWP).This functioned to exacerbate depression and deepen poverty. As participants withdrew, they experienced social isolation and less social support. Withdrawing from activities also included withdrawing from activities that could promote income generation or from social networks that could assist in finding out about such opportunities, thus deepening poverty.

You find that people are happy like I was before (finding out my HIV+ status) and now I'm not able to go and be happy like them and they will ask-why don't you go to this and that place. I don't want to see them or be with them... because I have accepted the situation... I don't go (out) (Case 15, KZN).

Excessive worry and intrusive thoughts also emerged as a common complaint (24 participants, 11 in KZN, 13 In NWP) which functioned to exacerbate depression. Excessive worry was commonly related to concerns about the impact of their positive HIV status on their families. A common worry was about making ends meet and the impact of their illness on their family, particularly their children:

I'm thinking about my children... they don't have anyone in case I die... To know that if I die I know that my children will suffer...If my parents were alive my children would have been okay (Case 11, KZN)

Thinking negatively about oneself also has the potential to trap people in a negative cycle of depression and poverty as reflected in the following quotation:

My rule is that I am a person who wants to continue with her studies...I.....but now I become ashamed even when a person says there is a course somewhere I see that I am not going to be able attend that course because I have a problem (Participant 12, NWP).

Short-temperedness and irritability was reported by almost half the respondents (16) (10 in KZN, 6 in KK) and contributed to increased withdrawal and social isolation of respondents.

Someone will say something but because I'm not okay at that time I'll say leave me alone. That's what makes them say I'm short-tempered. It's because of tiredness emotionally... because I've never told them about problems that are worrying me emotionally...we just end up not getting along like that (crying) (Case 7, KZN).

Other common symptoms mentioned included physiccal symptoms such as headaches, fatigue and sleep difficulties (23) (12 in KZN, 11 NWP), tearfulness and hyper-emotionality (14) (9 in KZN, 5 in NWP), and hopelessness and anhedonia (16) (9 in KZN, 7 in NWP).

\subsection{Current Coping Strategies and Possible Interventions}

\section{Current coping strategies}

The importance of social support for helping alleviate depressive symptoms was mentioned by nearly all the participants (31) (20 in KZN, 11 in NW). Emotional support in the form of someone to talk to within their families was emphasized, although having supportive friends was also important. Fewer indicated the usefulness of instrumental support in the form of grants, food, etc., (6) as well as informational or advisory support (8).

To be emotional depressed I can say it depends on the family that you are living with, and how they support you and the friend that you have. When you talk to them, they support you, and you won't be emotional depressed if you get support from your friend and at home... (Participant 1, KZN).

Spiritual help in the form of attending church also emerged as helpful by fewer respondents (8) (4 from KZN, 4 from NWP). Helping others was also suggested as helpful by 2 respondents, as was taking analgesics to cope. Positive thinking was mentioned by only one respondent.

Possible Psychosocial Interventions

In relation to more formal interventions, a number of respondents (15) (8 in KZN and 7 in NW) suggested that 
individual counselling provided at the clinic or at people's homes would be useful, with home visits being suggested for those who were too sick or poor to go to the clinic. Only three indicated that this service needed to be provided by mental health professionals or medical doctors. In relation to roles and functions, a few respondents indicated that nurses could help by identifying signs of depression. Some felt that nurses could provide counselling, but were ambivalent as to whether they would agree to this as reflected in the following quotation.

They (nurses) are not going to agree (to counselling). Some will agree and others will not... some are patient and others are not (Participant 7, NWP).

There was greater support for the use of community care givers and lay counsellors to provide psychosocial interventions. While some felt that this could be provided during their home visits, group-based interventions received the greatest amount of support, being suggested by 23 participants ( 8 from KZN and 15 from NWP) as being potentially useful given that people would be able to share their problems with people in similar situations.

If you are with people who are in the same situation and talk together maybe someone will tell you something that will help you and (you will realize) that you are not the only one who is facing problems (Participant 11, KZN).

Surprising, income generating interventions and employment opportunities to assist with poverty related stress were mentioned by relatively fewer respondents (9) (7 in KZN and 3 from NWP).

\section{DISCUSSION}

The emergent themes suggest that being HIV-positive per se was not viewed as a major cause of depression. Our data points to three factors that lead to depression in women who live with HIV, namely, stigma and discrimination; the stressors associated with living in poor socio-economic conditions; and stressful life events, particularly rejection/abuse/abandonment by partners, other family conflicts, multiple loss and other traumatic events. These findings are similar to previous studies $[11,31]$. While the social determinants of depression are now well established [17], this exploratory study illuminates the specific social factors that were reported to be associated with depression in South African women who live with HIV, providing important cultural and contextual information for possible interventions.

Our data also shows how the symptoms of depression, particularly withdrawal and social isolation, as well as intrusive negative thoughts about themselves, and constant worries, serve to exacerbate depression, trapping people in a negative depressive cycle. Symptoms of generalized anxiety disorder such as excessive worry, fa- tigue, irritability/short-temperedness and sleep disturbance also suggestive of co-morbid anxiety in some participants. Co-morbid depression and anxiety is common in patients with chronic illness [32] and at least one study in sub-Saharan Africa shows that mixed anxiety and depressive disorder is one of the most common categories of anxiety disorder in PLWHA [33].

Externalized stigma and discrimination associated with being HIV-positive is associated with withdrawal and to a lesser degree faulty or unhealthy thinking, which characterizes internalized stigma. Both these symptoms deepen depression through diminishing access to social support which was indicated by the majority of participants to assist in alleviating depressive symptoms (see Figure 1).

Living in conditions of poverty is a major contributing factor to depression in women in the general population in LMICs [17,34]. Our data suggests that this may be exacerbated in women living with HIV. Being poor and HIV-positive compounds marginalization as their illness makes it more difficult for them to seek or maintain employment. In addition, in African culture, women are typically responsible for raising children and are often burdened with having to care for deceased relatives' orphaned children under dire socio-economic circumstances. In the context of these social realities, symptoms of anxiety, particularly intrusive thoughts relating to concerns about not being able to meet the basic needs of their children, as well as concerns about who will take care of their children and families, should they die, served to exacerbate depression for these women (see Figure 1).

In the context of heightened vulnerability, the role of stressful life events in triggering depression is well documented, with bereavement, family conflict, separation/ divorce and exposure to violence and crime being some of the identified factors [17]. Being rejected/abused/ abandoned by partners, other family conflicts and to a lesser degree multiple loss and other traumas were the most common stressful life events that triggered depression in HIV-positive women. Rejection/abandonment by partners was associated with lower social and material support and greater financial difficulties and associated depressive symptoms, particularly constant worry and intrusive thoughts (see Figure 1).

Using a broad health systems framework these findings indicate the need for interventions at community, facility and organizational levels. At a community level, there is a need for culturally sensitive mental health promotion interventions to reduce stigma and discrimination as well as encourage income generation initiatives to promote sustainable livelihoods for women living with HIV. There is also a need for mental health promotion interventions to promote gender equity, with physical 


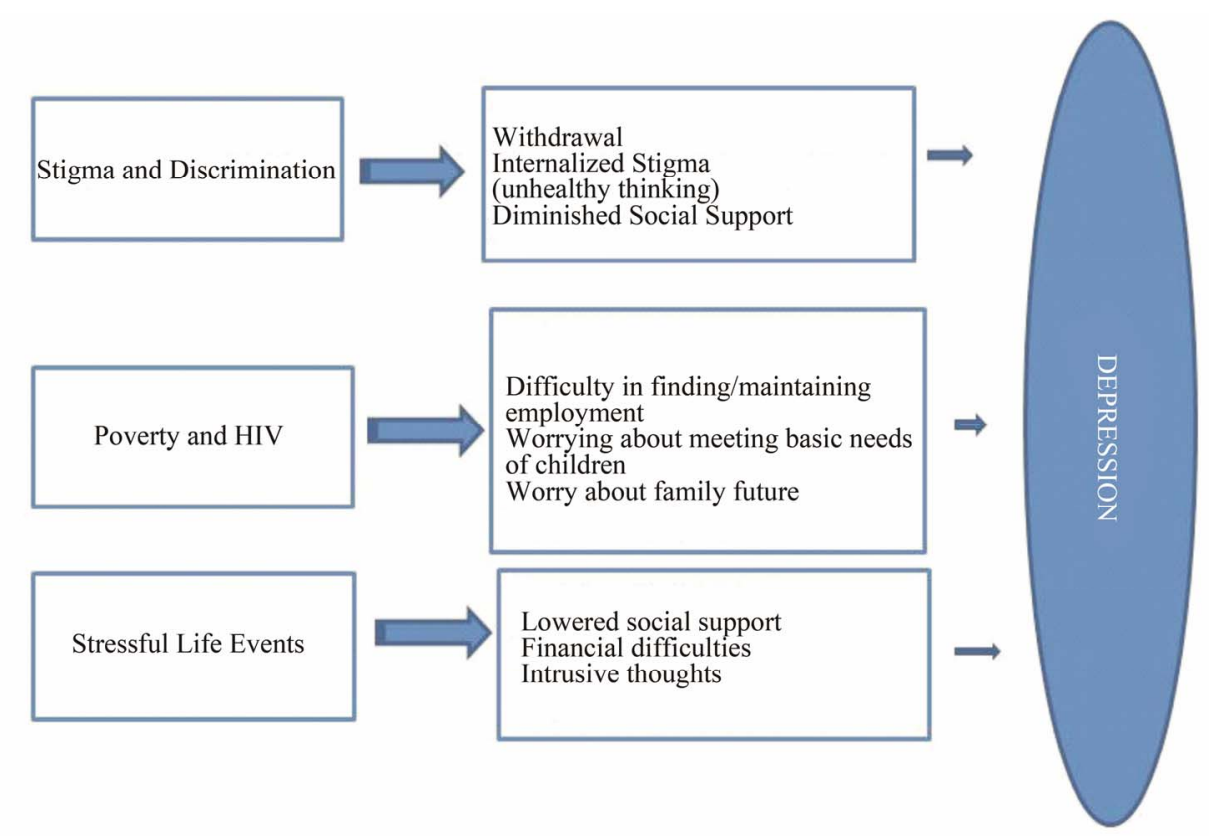

Figure 1. The role of social factors in depression in women living with HIV.

partner violence, being the strongest predictor of any lifetime mental disorder in women in South Africa [35]. These findings endorse the call for greater multi-sector engagement for the promotion of mental health in South Africa [36].

The promotion of social support for women living with HIV through the development of health enhancing social capital is also indicated. Social support was the most commonly identified coping mechanism by the participants. Group-based interventions that simultaneously promote social support and sustainable livelihoods have been shown to assist in improving the mental health of marginalized women in India [37].

At a health facility level, there is a need for identification of depression in PLWHA. Within a collaborative care approach, this needs to be accompanied by referral pathways for the initiation of psychotropic medication and psychosocial care in the form of group-based psychosocial interventions. For those too frail to attend such groups, individual counselling provided through a home visitation programme was suggested. Only a few participants indicated that such psychosocial services needed to be delivered by specialists. The concept of task sharing thus seems to be acceptable to service users. A collaborative-care task sharing model, requires, however, that at the organizational level of the health care system, roles and responsibilities of different PHC providers in the deliv- ery of the package of care are clearly identified and training and supervision provided. In relation to the re- engineered PHC system in South Africa, PHC nurses and doctors, trained lay counsellors who have historically done pre- and post-test HIV counselling, as well as general community care givers are potential resources for the delivery of a task-sharing package for PLWHA with depression. Previous research suggests that while PHC nurses may be trained to assist in the identification, referral and administration of follow-up psychotropic medication for mental health service users, they are unlikely to have the time to provide psychosocial intervention packages [22]. This suggests that trained lay counsellors and community care givers within the system be harnessed to play a greater role in this regard. Task sharing with this cadre of workers would, however, require strong supervision and support structures as well as structured manualised interventions [38-40].

In relation to the content of the care package, available resources include the World Health Organization's recently developed Mental Health Gap Action Programme (mhGAP). This provides algorythms for the identification and management of priority mental disorders including depression by PHC workers [41]. These guidelines have been integrated into a set of guidelines for a number of chronic diseases, including HIV and tuberculosis for PHC nurses and doctors in South Africa, called Primary Care 101 [42]. Referral for evidence-based counselling is recommended for less severe cases.

Our data suggests that group-based interventions, which provide opportunities for sharing problems with other people who have similar experiences, would resonate with local understandings of distress and healing and build on local strengths and support systems. Support groups have also been found helpful to people who suffer stigmatizing illnesses such as HIV/AIDS [43].

In relation to psychological therapeutic modalities that 
would be appropriate to adopt, IPT is useful for assisting people with existing interpersonal problems and dealing with situations or contexts that increase their vulnerability to the development of mental disorders [45]. It could thus be potentially useful to address the interpersonal issues that trigger depression in women with HIV such as externalized stigma, partner rejection and other interpersonal conflicts. An adapted group-IPT intervention run by trained community care givers in rural KwaZulu-Natal, which has one of the highest HIV prevalence rates in the country, has been shown to be a feasible and promising approach for alleviating depressive symptoms and building social support for women in South Africa [44].

Problem Solving Therapy (PST) is also useful for assisting with current existential problems, including socioeconomic difficulties. PST is a behavioural process which makes available a variety of response alternatives for dealing with a problematic situation, and increases the probability of selecting the most effective response from among these alternatives [46]. Two RCTs, one in Zimbabwe and one in South Africa, report positive outcomes for PST delivered within a task sharing model to people with depressive symptoms $[47,48]$.

CBT is potentially useful for dealing with symptoms of depression and co-morbid anxiety symptoms, particularly, negative and intrusive thoughts and excessive worry which serve to exacerbate depression. It is a structured short-term, present oriented psychotherapy for depression directed toward solving current problems and modifying dysfunctional (inaccurate or unhelpful) thinking and behaviour, as well as motivating people to begin to act on their problems through behavioural activation [49]. It has been successfully used within a task sharing approach for maternal depression in Pakistan [50].

It appears thus, that elements of all three evidencebased psychological interventions for depression in LMICs [18] could be harnessed for the development of an acceptable psychosocial intervention that could be delivered by trained lay counsellors/community care givers.

\section{CONCLUSIONS}

The results of this exploratory study endorse the need for multi-sector engagement in mental health promotion to address factors that trigger, maintain and exacerbate depression at a community level in PLWHA. These factors include stigma and discrimination, economic marginalization and gender inequities, with interventions to address these factors being central for the re-integration of PLWHA into society and the promotion of sustainable recovery in the long term. Working collaboratively with communities in the development of such interventions can also assist to empower communities to gain control over the social determinants of poor mental health, and in this instance, depression in women living with HIV, in particular.

In relation to treatment of depression in women living with HIV in South Africa, a collaborative care task sharing model is proposed that provides opportunities for limited referral for medication and emphasises group counselling, or individual counselling through a home visitation programme for those too frail to attend at a facility. Triggers and symptoms of depression reported by afflicted women suggest the applicability of a range of evidence-based Western derived techniques. CBT techniques could be included to foster the development of healthy thinking and reduce the most prominent symptoms of depression and co-morbid anxiety; PST techniques to develop problem solving skills to address social and materially based problems; and group-based IPT techniques to promote greater social support.

\section{ACKNOWLEDGEMENTS}

The authors would like to acknowledge the help of the following students and research assistants in the collection of the data: Letta Mosue, One Selohilwe, Hameeda Bassa, Elspeth Cornell, Candice Leith, Wandi Malinda, Namisile Mchunu, Philile Mngadi, Olwethu Mncono, Shannon Ownhouse, Shelley Rogers and Sifiso Shabangu.

This document is an output from a project funded by the UK Department for International Development (DFID) for the benefit of developing countries. However, the views expressed are not necessarily those of or endorsed by DFID, which can accept no responsibility for such views or information or any reliance placed on them. Funding to support the data collection and analysis was also received from the Health Economics and HIV/AIDS Research Division (HEARD) at the University of KwaZulu-Natal, South Africa.

\section{REFERENCES}

[1] Collins, P.Y., Patel, V., Joestl, S.S., March, D., Insel, T.R., et al. (2011) Grand challenges in global mental health. Nature, 475, 27-30. doi:10.1038/475027a

[2] Patel, V., Boyce, N., Collins, P.Y., Saxena, S. and Horton, R. (2011) A renewed agenda for global mental health. Lancet, 378, 1441-1442. doi:10.1016/S0140-6736(11)61385-8

[3] Seedat, S., Stein, D.J., Herman, A., Kessler, R., Sonnega, J., et al. (2008) Twelve-month treatment of psychiatric disorders in the South African Stress and Health Study (World Mental Health Survey Initiative). Social Psychiatry and Psychiatric Epidemiology, 43, 889-897. doi:10.1007/s00127-008-0399-9

[4] Ramokgopa, G. (2012) A milestone for mental health in South Africa. African Journal of Psychiatry, 15, 379.

[5] Mayosi, B.M., Lawn, J.E., van Niekerk, A., Bradshaw, D., Abdool, Karim, S.S., et al. (2012) Health in South Africa: Changes and challenges since 2009. Lancet, 380, 20292043. doi:10.1016/S0140-6736(12)61814-5

[6] Nakimuli-Mpungu, E., Bass, J.K., Alexandre, P., Mills, 
E.J., Musisi, S., et al. (2011) Depression, alcohol use and adherence to antiretroviral therapy in Sub-Saharan Africa: A systematic review. AIDS and Behavior, 16, 2101-2118. doi:10.1007/s10461-011-0087-8

[7] Peltzer, K., Friend-du Preez, N., Ramlagan, S. and Anderson, J. (2010) Antiretroviral treatment adherence among HIV patients in KwaZulu-Natal, South Africa. BMC Public Health, 10, 111. doi:10.1186/1471-2458-10-111

[8] Joska, J.A., Fincham, D.S., Stein, D.J., Paul, R.H. and Seedat, S. (2010) Clinical correlates of HIV-associated neurocognitive disorders in South Africa. AIDS and Behavior, 14, 371-378. doi:10.1007/s10461-009-9538-X

[9] Brandt, R. (2009) The mental health of people living with HIV/AIDS in Africa: A systematic review. African Journal of AIDS Research, 8, 123-133. doi:10.2989/AJAR.2009.8.2.1.853

[10] Lawler, K., Mosepele, M., Seloilwe, E., Ratcliffe, S., Steele, K., et al. (2011) Depression among HIV-positive individuals in Botswana: A behavioral surveillance. AIDS and Behavior, 15, 204-208. doi:10.1007/s10461-009-9622-2

[11] Freeman, M., Nkomo, N., Kafaar, Z. and Kelly, K. (2007) Factors associated with prevalence of mental disorder in people living with HIV/AIDS in South Africa. AIDS Care, 19, 1201-1209. doi:10.1080/09540120701426482

[12] Olley, B.O., Seedat, S. and Stein, D.J. (2006) Persistence of psychiatric disorders in a cohort of HIV/AIDS patients in South Africa: A 6-month follow-up study. Journal of Psychosomatic Research, 61, 479-484. doi:10.1016/j.jpsychores.2006.03.010

[13] Department of Health (2011) South African National Strategic Plan on HIV, STIs and TB (2012-2016). Department of Health, Pretoria.

[14] Lund, C., Kleintjes, S., Kakuma, R. and Flisher, A.J. (2010) Public sector mental health systems in South Africa: Inter-provincial comparisons and policy implications. Social Psychiatry and Psychiatric Epidemiology, 45, 393404. doi:10.1007/s00127-009-0078-5

[15] Sherr, L., Clucas, C., Harding, R., Sibley, E. and Catalan, J. (2011) HIV and Depression-A systematic review of interventions. Psychology, Health \& Medicine, 16, 493527. doi:10.1080/13548506.2011.579990

[16] Campbell, C. and Burgess, R. (2012) The role of communities in advancing the goals of the Movement for Global Mental Health. Transcultural Psychiatry, 49, 379-395. doi:10.1177/1363461512454643

[17] Patel, V., Lund, C., Hatherill, S., Plagerson, S., Corrigall, J., et al. (2010) Mental disorders: Equity and social determinants. In: Blas, E. and Kurup, A.S., Eds., Equity, Social Determinants and Public Health Programmes. World Health Organization, Geneva, 115-134.

[18] Dua, T., Barbui, C., Clark, N., Fleischmann, A., Poznyak, V., et al. (2011) Evidence-based guidelines for mental, neurological, and substance use disorders in low- and middle-income countries: Summary of WHO recommendations. PLOS Medicine, 8, e1001122. doi:10.1371/journal.pmed.1001122

[19] Ton, H., Koike, A., Hales, R.E., Johnson, J.A. and Hilty, D.M. (2005) A qualitative needs assessment for develop- ment of a cultural consultation service. Transcultural Psychiatry, 42, 491-504. doi:10.1177/1363461505055629

[20] Patel, V. and Prince, M. (2010) Global mental health: A new global health field comes of age. Journal of the American Medical Association, 303, 1976-1977. doi:10.1001/jama.2010.616

[21] Department of Health (1997) White paper for the transformation of the health system in South Africa. Department of Health, Pretoria.

[22] Petersen, I., Bhana, A., Campbell-Hall, V., Mjadu, S., Lund, C., et al. (2009) Planning for district mental health services in South Africa: A situational analysis of a rural district site. Health Policy Plan, 24, 140-150. doi:10.1093/heapol/czn049

[23] Tomlinson, M., Grimsrud, A.T., Stein, D.J., Williams, D.R. and Myer, L. (2009) The epidemiology of major depression in South Africa: Results from the South African stress and health study. South African Medical Journal, 99, 367-373.

[24] Department of Health (2011) The 2010 National Antenatal Sentinal HIV and Syphilis Prevalence Survey in South Africa. Department of Health, Pretoria.

[25] Kleinman, A. (1980) Patients and healers in the context of culture. University of California Press, Berkeley.

[26] Knoblauch, H. (2005) Focused ethnography. Forum Qualitative Sozialforschung/Forum: Qualitative Social Research, 6.

http://www.qualitative-research.net/index.php/fqs/article/ view/20/43

[27] Bhagwanjee, A., Parekh, A., Paruk, Z., Petersen, I. and Subedar, H. (1998) Prevalence of minor psychiatric disorders in an adult African rural community in South Africa. Psychological Medicine, 28, 1137-1147. doi:10.1017/S0033291798006965

[28] Rumble, S., Swartz, L., Parry, C. and Zwarenstein, M. (1996) Prevalence of psychiatric morbidity in the adult population of a rural South African village. Psychological Medicine, 26, 997-1007. doi:10.1017/S0033291700035327

[29] Cooper, P.J., Tomlinson, M., Swartz, L., Landman, M., Molteno, C., et al. (2009) Improving quality of motherinfant relationship and infant attachment in socio-economically deprived community in South Africa: Randomised controlled trial. British Medical Journal, 338, b974. doi:10.1136/bmj.b974

[30] Lincoln, Y.S. and Guba, E.G. (1985) Naturalistic inquiry.:: Sage, Beverly Hills.

[31] Gurung, R.A.R., Taylor, S.E., Kemeny, M. and Myers, H. (2004) "HIV is not my biggest problem": The impact of HIV and chronic burden on depression in women at risk for aids. Journal of Social and Clinical Psychology, 23, 490-511. doi:10.1521/jscp.23.4.490.40305

[32] Scott, K.M., Bruffaerts, R., Tsang, A., Ormel, J., Alonso, J., et al. (2007) Depression-anxiety relationships with chronic physical conditions: Results from the World Mental Health Surveys. Journal of Affective Disorders, 103, 113-120. doi:10.1016/j.jad.2007.01.015

[33] Olagunju, A.T., Adeyemi, J.D., Ogbolu, R.E. and Camp- 
bell, E.A. (2012) A study on epidemiological profile of anxiety disorders among people living with HIV/AIDS in a Sub-Saharan Africa HIV Clinic. AIDS and Behavior, 16, 2192-2197. doi:10.1007/s10461-012-0250-X

[34] Lund, C., Breen, A., Flisher, A.J., Kakuma, R., Corrigall, J., et al. (2010) Poverty and common mental disorders in low and middle income countries: A systematic review. Social Science \& Medicine, 71, 517-528. doi:10.1016/j.socscimed.2010.04.027

[35] Gass, J.D., Stein, D.J., Williams, D.R. and Seedat, S. (2010) Intimate partner violence, health behaviours, and chronic physical illness among South African women. South African Medical Journal, 100, 582-585.

[36] Skeen, S., Kleintjes, S., Lund, C., Petersen, I., Bhana, A., et al. (2010) "Mental health is everybody's business": roles for an intersectoral approach in South Africa. International Review of Psychiatry, 22, 611-623. doi:10.3109/09540261.2010.535510

[37] Kermode, M., Herrman, H., Arole, R., White, J., Premkumar, R., et al. (2007) Empowerment of women and mental health promotion: A qualitative study in rural Maharashtra, India. BMC Public Health, 7, 225. doi:10.1186/1471-2458-7-225

[38] Haffejee, S., Groeneveld, I., Fine, D., Patel, R. and Bowman, B. (2010) An assessment of counselling and support services for people living with HIV in Gauteng, South Africa: Findings of a baseline study. Ajar-African Journal of Aids Research, 9, 367-372. doi:10.2989/16085906.2010.545642

[39] Petersen, I., Ssebunnya, J., Bhana, A. and Baillie, K. (2011) Lessons from case studies of integrating mental health into primary health care in South Africa and Uganda. International Journal of Mental Health Systems, 5, 8. doi:10.1186/1752-4458-5-8

[40] Nulty, M. and Edwards, D. (2005) The experiences and needs of HIV/AIDS counsellors at a Soouth African hospital. Journal of Psychology in Africa, 15, 1-10.

[41] World Health Organization (2010) mhGAP Intervention Guide. World Health Organization, Geneva.

[42] University of Cape Town Lung Institute (2012) Primary Care 101. Department of Health, Pretoria.
[43] Davison, K.P., Pennebaker, J.W. and Dickerson, S.S. (2000) Who talks? The social psychology of illness support groups. American Psychologist, 55, 205-217. doi:10.1037/0003-066X.55.2.205

[44] Petersen, I., Bhana, A. and Baillie, K. (2012) The feasibility of adapted group-based interpersonal therapy (IPT) for the treatment of depression by community health workers within the context of task shifting in South Africa. Community Mental Health Journal, 48, 336-341. doi:10.1007/s10597-011-9429-2

[45] Cuijpers, P., van Straten, A., Smit, F., Mihalopoulos, C. and Beekman, A. (2008) Preventing the onset of depressive disorders: A meta-analytic review of psychological interventions. American Journal of Psychiatry, 165, 12721280. doi:10.1176/appi.ajp.2008.07091422

[46] D’Zurilla, T.J. and Goldfried, M.R. (1971) Problem solving and behavior modification. Journal of Abnormal Psychology, 78, 107-126. doi:10.1037/h0031360

[47] Chibanda, D., Mesu, P., Kajawu, L., Cowan, F., Araya, R., et al. (2011) Problem-solving therapy for depression and common mental disorders in Zimbabwe: piloting a taskshifting primary mental health care intervention in a population with a high prevalence of people living with HIV. BMC Public Health, 11, 828. doi:10.1186/1471-2458-11-828

[48] Van’t Hof, E., Stein, D.J., Marks, I., Tomlinson, M. and Cuijpers, P. (2011) The effectiveness of problem solving therapy in deprived South African communities: Results from a pilot study. BMC Psychiatry, 11, 156. $\underline{\text { doi:10.1186/1471-244X-11-156 }}$

[49] Beck, A.T. and Dozois, D.J. (2011) Cognitive therapy: Current status and future directions. Annual Review of Medicine, 62, 397-409. doi:10.1146/annurev-med-052209-100032

[50] Rahman, A., Malik, A., Sikander, S., Roberts, C. and Creed, F. (2008) Cognitive behaviour therapy-based intervention by community health workers for mothers with depression and their infants in rural Pakistan: A clusterrandomised controlled trial. Lancet, 372, 902-909. 